\title{
Should we adjust erythropoiesis-stimulating agent dosage to postdialysis hemoglobin levels? A pilot study
}

\author{
Nieves del Castillo ${ }^{1 \dagger}$, Patricia García-García ${ }^{1 \dagger}$, Antonio Rivero ${ }^{1}$, Alejandro Jiménez-Sosa², Manuel Macía', \\ María Adela Getino1, María Luisa Méndez¹, Javier García-Pérez ${ }^{1}$ and Juan F Navarro-González ${ }^{1,3^{*}}$
}

\begin{abstract}
Background: Predialysis hemoglobin $(\mathrm{Hb})$ may overestimate the true erithropoiesis-stimulating agents (ESA) requeriments. We tested whether predialysis $\mathrm{Hb}$ is a reliable predictor of the postdialysis level to better control ESA dosage, and evaluated the relation between ESA, Hb and cardiovascular events (CVE).

Methods: Cohort study including 67 stable hemodialysis patients. Pre- and post-dialysis Hb concentrations were measured, and ESA doses were calculated. A model to predict post-dialysis $\mathrm{Hb}$ is proposed. During 18 months follow-up, CVE, hospitalizations and mortality were collected.

Results: After dialysis, $\mathrm{Hb}$ cocentration rise by $6.1 \pm 5.6 \%$. Using postdialysis $\mathrm{Hb}$, the weight-adjusted ESA dosage would be lower respect to the prescription using predialysis Hb: $104 \pm 120$ vs $128 \pm 124 \mathrm{U} / \mathrm{kg} /$ week $(P<0.001)$. Using predialysis $\mathrm{Hb}, 40.2 \%$ of subjects had a Hb level above $12 \mathrm{~g} / \mathrm{dL}$, whereas this percent increased to $70.1 \%$ using postdialysis Hb. During the follow-up, 15 patients had a CVE, without differences in Hb levels respect to subjects without CVE. However, patients with CVE had received higher ESA doses: $186 \pm 180$ vs $111 \pm 98 \mathrm{U} / \mathrm{Kg} /$ week $(P=0.001)$. The prediction model is: Postdialysis $\mathrm{Hb}(\mathrm{g} / \mathrm{dL})=1.636+0.871 \times$ predialysis $\mathrm{Hb}^{*}(\mathrm{~g} / \mathrm{dL})+0.099 \times$ UF rate ${ }^{* *}$ $(\mathrm{mL} / \mathrm{kg} / \mathrm{h})-0.39$ for women ${ }^{* * *} .\left[\mathrm{R}^{2}=0.74 ;{ }^{*} P<0,001 ;{ }^{* *} P=0.001 ;{ }^{* * *} P=0.03\right)$.

Conclusions: Postdialysis $\mathrm{Hb}$ can be a better reflect of the real $\mathrm{Hb}$ level in hemodialysis patients. Using postdialysis $\mathrm{Hb}$ would avoid the use of inappropriately high ESA doses. The prediction of postdialysis $\mathrm{Hb}$ with an adjusted model would help us to identify those patients at risk for ESA overdosification.
\end{abstract}

\section{Background}

The introduction of erythropoiesis-stimulating agents (ESA) has been the most important breakthrough in the treatment of anemia associated to chronic kidney disease (CKD). However, concomitantly with the growing knowledge about anemia management with ESA, new clinical challenges have emerged, such as the definition of the optimal hemoglobin $(\mathrm{Hb})$ target for these patients. Moreover, this target has changed repeatedly based on security reasons [1-3]. Recent randomized clinical trials have shown

\footnotetext{
* Correspondence: jnavgon@gobiernodecanarias.org

${ }^{\dagger}$ Equal contributors

${ }^{1}$ Nephrology Service, University Hospital Nuestra Señora de Candelaria, Santa Cruz de Tenerife 38010, Spain

${ }^{3}$ Research Unit, University Hospital Nuestra Señora de Candelaria, Santa Cruz de Tenerife, Spain

Full list of author information is available at the end of the article
}

more frequent adverse events in patients treated to higher $\mathrm{Hb}$ targets, and therefore receiving higher ESA doses [47]. This opens the question about the potential harmful effects of ESA, specially in high doses, and their potential contribution to adverse outcomes in these patients [8]. In addition, the potential association between ESA doses and adverse outcomes lead to question whether ESA dosage must be adjusted based on pre- or post-dialysis $\mathrm{Hb}$ values in hemodialysis (HD) population.

Clasically, prescription of ESA in HD patients has been based on the $\mathrm{Hb}$ concentration measured before the dialysis session, when volume overload may underestimate the real concentration of serum $\mathrm{Hb}$. Diverse studies have described that serum $\mathrm{Hb}$ concentration varies during the $\mathrm{HD}$ session, and that $\mathrm{Hb}$ level is significantly different when it is measured before or after dialysis, or in the interdialysis period [9-12]. Therefore, predialysis $\mathrm{Hb}$

\section{Biomed Central}


measurement might result in an overestimation of ESA dosage, representing a potential risk regarding ESArelated complications.

In the present study, we measured the $\mathrm{Hb}$ and Hematocrit (Hct) levels before and after a dialysis session in a group of stable maintenance HD patients in order to evaluate the variation of $\mathrm{Hb}$ and Hct during a dialysis session, the differences in EPO requirements and the associated economic impact. In addition, we prospectively analyzed the cardiovascular events (CVE) over a period of 18 months, and the potential relationship with $\mathrm{Hb}$ levels and EPO doses. Finally, since $\mathrm{Hb}$ measurement after the dialysis is not an usual clinical practice, we propose an equation to predict the post-dialysis $\mathrm{Hb}$ concentration based on an adjusted model.

\section{Methods}

This cohort pilot study included 67 subjects in an outpatient hemodialysis centre at the University Hospital Nuestra Señora de Candelaria (Santa Cruz de Tenerife, Spain). Any research that is reported in this manuscript has been approved by the local Ethics Committee at the University Hospital Nuestra Señora de Candelaria, and has been carried out in compliance with the Helsinki Declaration. All patients gave informed consent to participate in the study.

All patients had CKD stage 5D, under maintenance HD for more than 6 months. There were 43 males and 24 females, with a mean age of $65 \pm 13$ years (range 31-85 years). All patients received bicarbonate hemodialysis three times weekly with polysulfone membranes $\left(1.8-2 \mathrm{~m}^{2}\right)$. The mean dialysis time was $237 \pm 19$ minutes (range 135-270 minutes). Regarding the underlying renal disease, $43 \%$ of patients had diabetic nephropathy. Sixty-one patients (91\%) were under EPO therapy. There were no patients with hepatitis B, hepatitis C or human immunodeficiency virus infection. All subjects were on a stable clinical condition with no cardiovascular events in the previous 3 months. Baseline characteristics of the patients are shown on Table 1.

We measured the serum concentrations of $\mathrm{Hb}$ and Hct before and after the midweek HD session. We collected the prescribed EPO dose and calculated the dosage adjustment using the predialysis $\mathrm{Hb}$ level, as well as the hypothetical dose adjustment using the postdialysis $\mathrm{Hb}$ concentration. We calculated the difference and savings in dosage of EPO by patient and week, and the estimated cost reduction. The evolution of serum $\mathrm{Hb}$ concentration during an interdialysis period was analyzed in a small group of 5 patients. Serum $\mathrm{Hb}$ level was measured immediately before and after the dialysis session, and at 4, 24 and 48 hours postdialysis. In addition, we developed an adjusted model for the estimation of
Table 1 Baseline characteristics of the patients

\begin{tabular}{ll}
\hline Age (yr) & $\mathbf{6 5 \pm 1 3}$ (range 31-85) \\
\hline Sex (male) -no. (\%) & $43(64)$ \\
Diabetes - no. (\%) & $29(43.2)$ \\
Underlying disease -no. (\%) & \\
- Diabetic nephropathy & $29(43.2)$ \\
- Nephroangiosclerosis & $15(22.38)$ \\
- Glomerulonephritis & $6(8.95)$ \\
- Policystic kidney disease & $8(11.94)$ \\
- Other & $9(13.53)$ \\
Charlson Comorbidity Index & $6.08 \pm 2.18$ \\
Time of dialysis (minutes) & $237 \pm 19.58$ \\
Kt-V & $1.28 \pm 0.22$ \\
Ultrafiltration (ml/kg/h) & $8.03 \pm 2.98$ (range 1.51-16.27) \\
EPO dose per week (U) & $8,059 \pm 7,712$ \\
EPO dose per Kg and week (U) & $118 \pm 120.24$ \\
Type of EPO-no. (\%) & \\
- darbepoetin a & $11(16.4)$ \\
- epoetin a & $16(23.8)$ \\
- epoetin $\beta$ & $34(50.7)$ \\
- without EPO & $6(9)$ \\
\hline
\end{tabular}

the postdialysis $\mathrm{Hb}$ concentration based on gender, predialysis $\mathrm{Hb}$ concentration and ultrafiltration (UF) rate.

During a follow-up period of 18 months, CVE, hospitalizations and mortality were recorded in order to analyze the potential relationship with $\mathrm{Hb}$ levels and EPO doses. The Charlson Comorbidity Index (CCI) [13], a score that includes age and comorbid conditions to which a specific weight is assigned, was used for valoration of comorbidity in each patient. Information was recorded by researchers from updated medical records. This index is used to adjust by comorbid conditions in longitudinal studies, and it has been specifically validated for patients with end-stage renal disease under dialysis therapy [14].

\section{Statistical analysis}

Results for quantitative variables are expressed as mean and standard deviation. Results for categorical variables are expressed with frequencies and percentages. Proportions were compared using the Chi-square test. Within groups measures for continuous variables were compared with Wilcoxon test and between groups comparison were carried out using the Mann-Whitney $U$ (asymptotic test) test and Wilkoxon-Mann-Whitney test (exact test). Differences in Hb serum concentration measured at predialysis, immediately postdialysis, and 4, 24 and $48 \mathrm{~h}$ after the end of the dialysis session were tested using the Wilcoxon rank test. Linear regression analysis 
was used to predict the postdialysis hemoglobin concentration using the predialysis hemoglobin level, the hourly UF rate $(\mathrm{mL} / \mathrm{kg} / \mathrm{hour})$ and gender as the independent variables. Risk of CVE according to ESA dose was calculated using partial Cox regression analysis, and the results are expressed as Hazard Ratio and its 95\% confidence interval. As only 15 cardiovascular events occurred, the Cox models presented are not cumulative, each used model is individual. Statistical analyses were performed with StatXact v. 5.0.3 (Cytel Co., MA), STATISTICA v. 7.1 (StatSoft, OK) and SPSS v. 17.0 (Chicago, IL). $P$ values lower than 0.05 were considered statistically significant.

\section{Results}

The mean predialysis and postdialysis $\mathrm{Hb}$ concentrations were $11.7 \pm 1.1 \mathrm{~g} / \mathrm{dL}$ and $12.5 \pm 1.2 \mathrm{~g} / \mathrm{dL}$, respectively $(P<0.001)$. The mean intradialytic percent variation $(\% \Delta)$ of $\mathrm{Hb}$ and Hct levels were $6.1 \pm 5.6 \%$ (range: -6.5 to 17.27 ) and $5.8 \pm 5.6 \%$ (range: -9.3 to 17.1 ), respectively. The mean weight loss during dialysis was $2.19 \pm 0.79 \mathrm{~kg}$ (Range: 0.5 to $3.8 \mathrm{~kg}$ ), with a mean hourly UF rate of $8.03 \pm 2.98 \mathrm{~mL} / \mathrm{kg} / \mathrm{h}$ (range 1.51 to $16.27 \mathrm{~mL} / \mathrm{kg} / \mathrm{h}$ ). When comparing patients according to the UF volume, in subjects with an UF $>2500 \mathrm{~mL} /$ session the mean $\% \Delta$ of $\mathrm{Hb}$ and Hct were $9.2 \pm 4.8 \%$ and $9 \pm 4.4 \%$, respectively, significantly higher than those observed in patients with an UF rate $<2500 \mathrm{~mL} / \mathrm{session}: 3.9 \pm 5.2 \%$ and $3.8 \pm 5.3 \%$, respectively $(P<0.001)$. Regarding the changes in serum $\mathrm{Hb}$ concentration during the interdialysis period, a statistical significant difference was found between the preand the immediately postdialysis $\mathrm{Hb}$ levels $(P=0.043)$. However, no differences were found between the immediately postdialysis $\mathrm{Hb}$ concentration and those at $4 \mathrm{~h}$ $(P=0.20), 24 \mathrm{~h} \quad(P=0.34)$ and $48 \mathrm{~h}(P=0.08)$ after dialysis.

According to KDOQI guidelines [1], using the predialysis measurements, $37.3 \%$ of subjects had an adequate serum $\mathrm{Hb}$ concentration (11-12 g/dL), whereas 15 subjects (22.3\%) had an inadequately low $\mathrm{Hb}$ level and 27 patients $(40.2 \%)$ had a $\mathrm{Hb}$ concentration above $12 \mathrm{~g} / \mathrm{dL}$. However, when postdialysis determinations were used, $70.1 \%$ of patients had a serum $\mathrm{Hb}$ concentration inadequately elevated (Table 2 ). When postdialysis measurement was used, 6 out of the 15 patients (40\%) with a predialysis $\mathrm{Hb}$ below $11 \mathrm{~g} / \mathrm{dL}$ had a $\mathrm{Hb}$ concentration within the KDOQI target, whereas 16 out of the 25 patients (64\%) with an adequate predialysis $\mathrm{Hb}$ level showed a postdialysis $\mathrm{Hb}$ concentration above $12 \mathrm{~g} / \mathrm{dL}$.

Sixty-one patients (91\%) were treated with EPO at the time of the study. No baseline differences were found between the patients with and without EPO in any variable (Table 3). We analysed the hypothetical dosage adjustment for EPO using the postdialysis $\mathrm{Hb}$ concentration
Table 2 Patients categorized according to pre and postdialysis $\mathrm{Hb}$

\begin{tabular}{lcccc}
\hline Hemoglobin (g/dL) & \multicolumn{3}{l}{ Postdialysis } & \\
\cline { 3 - 5 } & & Low $(<\mathbf{1 1})$ & Normal (11-12) & High $(>\mathbf{1 2})$ \\
\hline Postdialysis & Low $(<11)$ & 5 & 6 & 4 \\
& & $7.5 \%$ & $9.0 \%$ & $6.0 \%$ \\
Normal (11-12) & 1 & 8 & 16 \\
& $1.5 \%$ & $11.9 \%$ & $23.9 \%$ \\
High $(>12)$ & 0 & 0 & 27 \\
& $.0 \%$ & $.0 \%$ & $40.3 \%$ \\
\hline
\end{tabular}

as reference. If this determination was used, the weekly prescribed EPO dose would be significantly lower than the real EPO prescription based on predialysis $\mathrm{Hb}$ measurement $(7,03 \pm 7,765$ vs $8,23 \pm 8,045$ U; $P<0.001)$. After adjusting for weight, the hypothetical EPO dosage using the postdialysis $\mathrm{Hb}$ concentration could be reduced by 18.7\% (EPO dosage using predialysis $\mathrm{Hb}, 128 \pm 124 \mathrm{U} / \mathrm{kg} /$ week; EPO dosage using postdialysis $\mathrm{Hb}, 104 \pm 120 \mathrm{U} / \mathrm{kg} /$ week).

The linear regression model to predict the postdialysis $\mathrm{Hb}$ concentration is as follows: Postdialysis $\mathrm{Hb}(\mathrm{g} / \mathrm{dL})=$ $1.636+0.871 \mathrm{x}$ predialysis $\mathrm{Hb}^{*}(\mathrm{~g} / \mathrm{dL})+0.099 \times \mathrm{UF}$ rate*** $(\mathrm{mL} / \mathrm{kg} / \mathrm{h})-0.39$ for women ${ }^{* * * * *}$. The adjusted coefficient of determination $\left(\mathrm{R}^{2}\right)$ was 0.74 ("predialysis $\mathrm{Hb}$, $P<0.001$; **UFR, $P=0.001$; **** gender, $P=0.031$ ).

During the 18 months follow-up, 15 (25\%) patients had a CVE (2 stroke, 4 coronary disease, 2 cardiac arrhythmia, 1 peripheral vascular disease, 4 arteriovenous fistula thrombosis and 2 mesenteric ischemia). No differences were found between patients with and without CVE on Hb levels $(11.2 \pm 1.43 \mathrm{mg} / \mathrm{dL}$ vs $11.9 \pm 1.02 \mathrm{mg} / \mathrm{dL}$, respectively; $P=0.14$ ). However, patients who had a CVE had received higher mean doses of EPO than those without events: $12,133 \pm 10,562 \mathrm{U} /$ week vs $7,615 \pm 6,963 \mathrm{U} /$ week; $P=0.037$. Adjusted by weight the differences were $186 \pm 180$ vs $111 \pm 98 \mathrm{U} / \mathrm{Kg} /$ week $(P=0.001)$. None of the 6 patients without EPO therapy presented any CVE. We investigated whether comorbidities, expressed as Charlson index, or adequate dialysis (as measured by $\mathrm{Kt} / \mathrm{V}$ ), were confounding factors associated with CVE and EPO dose. No association was found neither between Charlson index and CVE $(r=0.11 ; P=0.19)$, nor EPO dose $(r=0.04$; $P=0.37$ ). Regarding $\mathrm{Kt} / \mathrm{V}$, this parameter was similar in patients with and without CVE $(1.3 \pm 0.19$ vs $1.3 \pm 0.23$, respectively), and no association was found between $\mathrm{Kt} / \mathrm{V}$ and EPO dose $(\mathrm{r}=0.19 ; P=0.58)$. Partial Cox regression analysis showed that controlling for ischemic heart disease and heart failure, ESA dose is a risk factor for CVE. However, the confounding effect of age, arrthymia, diabetes, peripheral vascular disease and stroke is unclear (Table 4). Frequency of hospitalization was significantly higher in 
Table 3 Baseline comorbidities categorized by ESA dose

\begin{tabular}{|c|c|c|c|}
\hline Comorbidity - N (\%) & $\begin{array}{l}\text { ESA dose (>18000 IU/week) } \\
\mathrm{N}=7\end{array}$ & $\begin{array}{l}\text { ESA dose }(\leq 18000 \text { IU/week }) \\
N=60\end{array}$ & $P$ \\
\hline Diabetes & $3(42.9)$ & $26(43.3)$ & 0.99 \\
\hline Ischemic Heart Disease & $1(14.4)$ & $20(33.3)$ & 0.41 \\
\hline Heart failure & $1(14.3)$ & $11(18.3)$ & 0.99 \\
\hline Peripheral vascular disease & $3(42.9)$ & $12(20)$ & 0.18 \\
\hline Stroke & $0(0)$ & $7(11.7)$ & 0.99 \\
\hline \multicolumn{4}{|l|}{ Chronic Obstructive } \\
\hline Pulmonary Disease (COPD) & $1(14.3)$ & $16(26.7)$ & 0.67 \\
\hline Arrhytmias & $2(28.6)$ & $11(18.3)$ & 0.61 \\
\hline Tumoral History & $2(28.6)$ & $7(11.7)$ & 0.24 \\
\hline Hepatopathy & $1(14.3)$ & $3(5)$ & 0.36 \\
\hline Hypertension & $7(100)$ & $58(96.7)$ & 0.99 \\
\hline
\end{tabular}

patients with CVE. Likewise, length of stay was also higher in patients with CVE (6 days [range, 3 to 12]) than in those without CVE (0 days [range, 0 to 7 ]); $P=0.016$ ). A total of 13 deaths occurred during follow-up, with an increase in the probability of death in patients with CVE (53\% vs 9.63\%; $P<0.001)$.

Finally, the aplication of postdialysis $\mathrm{Hb}$ to calculate the EPO dosage was associated with a reduction in cost:

Table 4 Partial Cox regression models to predict CVE controlling by age and comorbidities

\begin{tabular}{|c|c|c|c|}
\hline & HR & $95 \% \mathrm{Cl}$ & $P$ \\
\hline \multicolumn{4}{|l|}{ Model 1} \\
\hline EPO dose (IU/week) & 1.015 & $1.010-1.020$ & 0.032 \\
\hline Ischemic heart disease & 2.66 & $0.920-7.650$ & 0.069 \\
\hline \multicolumn{4}{|l|}{ Model 2} \\
\hline EPO dose (IU/week) & 1.0015 & $1.001-1.002$ & 0.049 \\
\hline Heart failure & 2.29 & $0.710-7.270$ & 0.16 \\
\hline \multicolumn{4}{|l|}{ Model 3} \\
\hline EPO dose (IU/week) & 1.00 & 0.999-1.001 & 0.058 \\
\hline Stroke & 1.72 & $0.380-7.750$ & 0.47 \\
\hline \multicolumn{4}{|l|}{ Model 4} \\
\hline EPO dose (IU/week) & 1.00 & $0.999-1.001$ & 0.06 \\
\hline Age (years) & 1.005 & $0.967-1.045$ & 0.79 \\
\hline \multicolumn{4}{|l|}{ Model 5} \\
\hline EPO dose (IU/week) & 1.000 & $0.999-1.001$ & 0.065 \\
\hline Arrythmia & 1.17 & $0.330-4.170$ & 0.80 \\
\hline \multicolumn{4}{|l|}{ Model 6} \\
\hline EPO dose (IU/week) & 1.000 & $0.999-1.001$ & 0.094 \\
\hline Diabetes & 0.468 & $0.163-1.345$ & 0.159 \\
\hline \multicolumn{4}{|l|}{ Model 7} \\
\hline EPO dose (IU/week) & 1.000 & 0.999-1.001 & 0.105 \\
\hline Peripheral vascular disease & 1.702 & $0.539-5.372$ & 0.36 \\
\hline
\end{tabular}

$101 \pm 111$ vs $124 \pm 116$ euros/patient/week, respectively $(P<0.001)$. In our dialysis center, for the 67 patients included in the study, this action would have saved 83,214 euros (\$118,858)/year.

\section{Discussion}

The main finding of our study is that the use of postdialysis $\mathrm{Hb}$ concentration to monitor and adjust EPO dosage would result in a significant reduction of EPO requeriments and costs. Specifically, this action in the present study was associated with a mean EPO dose decrease of $18.7 \%(\mathrm{U} / \mathrm{Kg} /$ week), and a mean cost reduction of 1,242 euros/patient/ year ( $\$ 1,774 /$ patient/year). In addition, we present a simple model to estimate the postdialysis $\mathrm{Hb}$ level based on predialysis $\mathrm{Hb}$, UF rate and gender. Our suggestion about the use of postdialysis $\mathrm{Hb}$ level to adjust and monitor ESA dosage may be a relevant issue, specially at the present moment, when the emergence of safety concerns and the changes in clinical practice recommendations have influenced physician practice in terms of reduction of target $\mathrm{Hb}$, use of ESA and dosing regimens [15].

The Food and Drug Administration has recently announced that ESA should be prescribed under a risk management programme (the Risk Evaluation and Mitigation Strategy), since results from three recent randomized controlled trials - the Correction of Hemoglobin and Outcomes in Renal Insufficiency (CHOIR) [4], the Cardiovascular Risk Reduction by Early Anemia Treatment with Epoetin Beta (CREATE) [5], and the Trial to Reduce Cardiovascular Events with Aranesp Therapy (TREAT) [6] - showed that assigned chronic kidney disease patients (not in dialysis) to intervention with an ESA to achieve a high versus a low $\mathrm{Hb}$ target was associated with an increased risk of myocardial infarction, stroke and death. However, almost 10 years before, the Normal Hematocrit Trial (NHCT) [16], a study in which more than $1200 \mathrm{HD}$ patients with congestive heart 
failure or ischemic heart disease were randomized to target Hct values of $42 \%$ (normal Hct group) and 30\%, had to be stopped prematurely by the Data Safety Monitoring Board because of concerns of increased cardiovascular disease risk and mortality in the normal Hct arm.

Although the majority of studies related to anemia in $\mathrm{HD}$ have used predialysis $\mathrm{Hb}$ and Hct values, several works have analysed the postdialysis values of Hb, showing important results. Vlassopoulos et al. [9] measured $\mathrm{Hb}$ and Hct in 15 stable patients before the HD sesion, and 24, 48 and 72 hours in the interdialysis period. They observed a significant $24 \mathrm{~h}$ postdialysis rise in $\mathrm{Hb}$ and Hct as compared to the predialysis level, with a gradual decrease reaching non-significant differences before the next HD session. Similar findings were reported by Movilli et al. [10] and Bellizzi et al. [12]. These authors observed that $\mathrm{Hb}$ and Hct levels after dialysis were similar to those observed immediately at the end of the HD session, and that these concentrations were significantly higher than the predialysis ones. Similarly, a significant increment in $\mathrm{Hb}$ and Hct levels after the HD procedure was observed in our study. The mean percent increase in the $\mathrm{Hb}$ and Hct values were $6.1 \%$ and $5.8 \%$, respectively, and rise to around $9 \%$ in patients with a body weight loss $\geq 2.5 \mathrm{~kg} / \mathrm{session}$. Moreover, serum $\mathrm{Hb}$ concentrations measured at 4, 24 and 48 hours postdialysis remained elevated as compared with the predialysis $\mathrm{Hb}$ measurement, without significant differences respect to the immediately postdialysis $\mathrm{Hb}$ level. According to KDOQI guidelines [1], using postdialysis measurements, $70.1 \%$ of our patients had a serum $\mathrm{Hb}$ above $12 \mathrm{~g} / \mathrm{dL}$. Importantly, this represents that $64 \%$ of patients with a normal $\mathrm{Hb}$ target based on predialysis $\mathrm{Hb}$ concentration had an inadequately high $\mathrm{Hb}$ level when postdialysis determinations were used. These findings indicate that during the first 24-48 hours after the HD session a slow reequilibration occurs, first affecting to the extravascular space, and then to the intravascular compartment $[10,12]$, suggesting that HD patients present most of the time a $\mathrm{Hb}$ and Hct levels clearly higher (up to $15 \%$ ) than the predialysis values [9]. This results in the potential exposition of these patients to excessively high $\mathrm{Hb}$ and Hct concentrations for a prolonged period.

During the 18 months of follow-up in our study, 25\% of patients had a CVE. There were no differences regarding $\mathrm{Hb}$ levels between patients with and without CVE. Conversely, patients who had a CVE had received significantly higher EPO doses than those without events. This relationship was not affected by some baseline comorbidities or dialysis adequacy, but probably the small sample size makes unclear the effect of other (i.e. diabetes, age, arrthymias, peripheral vascular disease and stroke). In addition, no CVE were observed in the 6 patients without ESA therapy. This observation points to the potential adverse outcomes associated with ESA administration, which has been suggested by other studies. Using data from the United States Renal Data System administrative claims, a retrospective cohort study of more than 90,000 prevalent HD patients showed a significant nonlinear relationship between increased epoetin dose and mortality [17]. In another study that comprised more than 40,000 maintenance HD patients, an association between erythropoietin exposure and mortality over 3 years was observed at very high doses (> 20,000 units/week) [18]. To further analyze the relationship among patient comorbidity, ESA dosage, and evolution with death hospitalization, myocardial infarction, stroke and heart failure as the primary compound objective, a secondary analysis of the CHOIR study was recently performed [8]. In the adjusted models, the risk associated with randomization to the high- $\mathrm{Hb}$ group was not significant $(\mathrm{p}=0.49)$, whereas high-dose erythropoietin dosage was associated with a $57 \%$ higher risk of the main variable (HR 1.57; CI: 1.04 to $2.36, \mathrm{p}=0.03$ ). Therefore, although the results of these studies did not prove causality, they suggested that high ESA dose rather than the $\mathrm{Hb}$ level was associated with adverse outcome, reinforcing the actual recommendations about the strict adjustment of ESA dosage and the close monitorization of $\mathrm{Hb}$ levels.

\section{Conclusion}

In conclusion, our results highlight the potential importance of postdialysis $\mathrm{Hb}$ concentration to monitor the $\mathrm{Hb}$ and Hct target levels, and to adequately adjust the ESA dosing regimen. The use of postdialysis $\mathrm{Hb}$ would avoid exposure of patients to inadequately high $\mathrm{Hb}$ and Hct levels during the interdialysis period, as well as to excessive ESA doses. This may be especially relevant in the current scenario: the optimal $\mathrm{Hb}$ target is not yet established, with serious safety concerns regarding ESA therapy. Since the measurement of postdialysis $\mathrm{Hb}$ concentration might be an unfeasible practice in many HD units, we propose an adjusted model to predict this parameter. The prediction of postdialysis $\mathrm{Hb}$ with an adjusted model help us to identify those patients at risk for overdosification of ESA, and might be associated with beneficial effects regarding cardiovascular morbidity and mortality. In addition, this strategy may result in lower ESA requeriments, or even may lead to the avoidance of ESA therapy in several patients, with a beneficial impact on the economic cost. From this economical perspective, the estimation of ESA dosage based on postdialysis $\mathrm{Hb}$ concentration would represent a mean saving of $18.5 \%$, approximately 1,242 euros (\$1,774/patient/year).

Competing interests

The authors declare that they have no competing interests. 


\section{Authors' contributions}

NC, PGG, JGP, JFNG have participated on the protocol designed, coordination of the study, analysis of data, and drafted the manuscript. AR, MM, MAG, MLM participate in data collection and interpretation, and preparation of the manuscript after the draft suggested by the previous authors. AJS, NC and PGG performed the statistical analysis. NC, PGG and JFNG participated in the corrections of the final draft of the manuscript. All authors have read and approved the final version of the manuscript.

\section{Acknowledgements}

Research activity by JFNG is supported by "Programa de Intensificación de la Actividad Investigadora" (ISCIII/Comunidad Autónoma de Canarias). We thank to ACINEF for funding publication costs.

\section{Author details}

${ }^{1}$ Nephrology Service, University Hospital Nuestra Señora de Candelaria, Santa Cruz de Tenerife 38010, Spain. ${ }^{2}$ MixedResearch Unit CHUC-ULL, Hospital Universitario de Canarias, La Laguna, Spain. ${ }^{3}$ Research Unit, University Hospital Nuestra Señora de Candelaria, Santa Cruz de Tenerife, Spain.

Received: 11 October 2011 Accepted: 18 June 2012

Published: 16 July 2012

\section{References}

1. KDOQI Clinical Practice Guideline and Clinical Practice Recommendations for anemia in chronic kidney disease: 2007 update of hemoglobin target. Am J Kidney Dis 2007, 50:471-530.

2. Locatelli F, Aljama P, Canaud B, Covic A, De Francisco A, Macdougall IC, Wiecek A, Vanholder R, Anaemia Working Group of European Renal Best Practice (ERBP): Target haemoglobin to aim for with erythropoiesisstimulating agents: a position statement by ERBP following publication of the Trial to Reduce Cardiovascular Events with Aranesp Therapy (TREAT) Study. Nephrol Dial Transplant 2010, 25:2846-2850.

3. U.S Food and Drug Administration. Safety Communication: Modified dosing recommendations to improve the safe use of Erythropoiesis-Stimulating Agents (ESAs) in chronic kidney disease. [http://www.fda.gov/Drugs/DrugSafety/ ucm259639.htm]

4. Singh AK, Szczech L, Tang KL, Barnhart H, Sapp S, Wolfson M: Reddan D for the CHOIR investigators: Correction of anemia with Epoetin alfa in chronic kidney disease. N Engl J Med 2006, 355:2085-2098.

5. Drüeke TB, Locatelli F, Clyne N, Eckardt KU, Macdougall I, Tsakiris D, Burger $\mathrm{HU}$, Scherhag A, for the CREATE investigators: Normalization of haemoglobin level in patients with chronic kidney disease and anemia. N Engl J Med 2006, 355:2071-2084.

6. Pfeffer MA, Burdmann EA, Chen CY, Cooper ME, de Zeeuw D, Eckardt KU, Feyzi JM, Ivanovich P, Kewalramani R, Levey AS, Lewis EF, McGill JB, McMurray JJ, Parfrey P, Parking HH, Remuzzi G, Singh AK, Solomon SD, Toto R SD, TREAT Investigators: A Trial of Darbepoetin Alfa in Type 2 Diabetes and Chronic Kidney Disease. N Engl J Med 2009, 361:2019-2032.

7. Heinze G, Sainz A, Horl WH, Oberbauer R: Mortality in renal transplant recipients given erythropoietins to increase haemoglobin cocentration: cohort study. BMJ 2009, 339:b4018.

8. Szczech LA, Barnhart HX, Inrig JK, Reddan DN, Sapp S, Califf RM, Patel UD, Singh AK: Secondary analysis of the CHOIR trial epoetin-alpha dose and achieved hemoglobin outcomes. Kidney Int 2008, 74:791-798.

9. Vlassopoulos D, Sonikian M, Dardioti V, Hadjiconstantinou V: Target Haematocrit during erythropoietin treatment in dialysis patients. Which value is 'true-functional haematocrit? Nephrol Dial Transplant 1999, 14:1340-1341.

10. Movilli E, Pertica N, Cancarini G, Brunori G, Scolari F, Maiorca R: Predialysis versus postdialysis hematocrit evaluation during erythropoietin therapy. Am J Kidney Dis 2002, 39:850-853.

11. Korzets A, Ori Y, Zevin D, Gafter U: Posthemodialysis haemoglobin levels: overdue or not? Am J Kidney Dis 2002, 40:873.

12. Bellizzi V, Minutolo R, Terracciano V, lodice C, Giannattasio P, De Nicola L, Conte G, Di Lorio BR: Influence of the cyclic variation of hydration status on hemoglobin levels in hemodialysis patients. Am J Kidney Dis 2002, 40:549-555.

13. Charlson ME, Pompei P, Ales KL, MacKenzie CR: A new method of classifying prognostic comorbidity in longitudinal studies: Development and validation. J Chronic Dis 1987, 40:373-383.
14. Beddhu S, Bruns FJ, Saul M, Seddon P, Zeidel ML: A simple comorbidity scale predicts clinical outcomes and costs in dialysis patients. Am J Med 2000, 108:609-613.

15. Regidor D, McClellan WM, Kewalramani R, Sharma A, Bradbury BD: Changes in erythropoiesis-stimulant agent (ESA) dosing and haemoglobin levels in US non-dialysis chronic kidney disease patients between 2005 and 2009. Nephrol Dial Transplant 2011, 26:1583-1591.

16. Besarab A, Bolton WK, Browne JK, Egrie JC, Nissenson AR, Okamoto DM, Schwab SJ, Goodkin DA: The effects of normal as compared with low hematocrit values in patients with cardiac disease who are receiving hemodialysis and epoetin. N Engl J Med 1998, 339:584-590.

17. Zhang Y, Thamer M, Stefanik K, Kaufman J, Cotter DJ: Epoetin requirements predict mortality in hemodialysis patients. Am J Kidney Dis 2004, 44:866-876

18. Bradbury BD, Wang O, Critchlow CW, Rothman KJ, Heagerty P, Keen M, Acquavella JF: Exploring relative mortality and epoetin alpha dose among hemodialysis patients. Am J Kidney Dis 2008, 51:62-70.

doi:10.1186/1471-2369-13-60

Cite this article as: Castillo et al:: Should we adjust erythropoiesisstimulating agent dosage to postdialysis hemoglobin levels? A pilot study. BMC Nephrology 2012 13:60.

\section{Submit your next manuscript to BioMed Central and take full advantage of:}

- Convenient online submission

- Thorough peer review

- No space constraints or color figure charges

- Immediate publication on acceptance

- Inclusion in PubMed, CAS, Scopus and Google Scholar

- Research which is freely available for redistribution 